\title{
Characterization of Glucose Oxidase-Modified Poly(phenylenediamine)-Coated Electrodes in Vitro and in Vivo: Homogeneous Interference by Ascorbic Acid in Hydrogen Peroxide Detection
}

\author{
John P. Lowry, Karl McAteer, Satea S. El Atrash, Adrlenne Duff, and Robert D. O'Nell'" \\ Department of Chemistry, University College Dublin, Belfield, Dublin 4, Ireland
}

The response of glucose oxidase (GOx) modified poly( $a$ phenylenediamine) coated Pt disk electrodes to glucose was well-behaved with a rapid response time and displaying Michaelis-Menten kinetics. However, the glucose response was lowered in a concentration-dependent manner by ascorbic acid when the glucose calibrations were carried out in solutions containing this reducing agent. The possibility of a homogeneous redox reaction in which the $\mathrm{H}_{2} \mathrm{O}_{2}$ generated by the enzymatic oxidation of glucose at the $\mathrm{GOx} /$ polymer surface is consumed by ascorbate was investigated. Similar "negative" interference at GOX-modified carbon powder electrodes not involving membranes and for $\mathrm{H}_{2} \mathrm{O}_{2}$ calibrations at bare $\mathrm{Pt}$ electrodes supported the hypothesis. The observation that this interference could be blocked by the chelating agent EDTA suggests that the homogeneous reaction is catalyzed by trace metal ion impurities in solution. A model for the homogeneous reaction based on these experimental findings is proposed and tested by comparing quiescent and stirred solutions. No homogeneous interference by uric acid was observed. The electrodes were found to be free from lipid fouling in vitro, and experiments monitoring brain glucose levels in vivo indicate the absence of the homogeneous reaction in this environment. The results highlight the need to test each individual assay procedure involving $\mathrm{H}_{2} \mathrm{O}_{2}$ under relevant conditions for both positive and negative interference by ascorbic acid.

The search for the ideal glucose sensor continues to be one of the main focuses of biosensor research despite 3 decades of intense investigation since the development of the first electrochemical glucose sensor by Clark and Lyons in $1962 .{ }^{1}$ This is primarily due to the important role of such a glucose monitoring sensor in industrial ${ }^{2,3}$ and clinical ${ }^{4-6}$ applications, ranging from the analysis of fermentation media ${ }^{2}$ to the development of the artificial $\beta$-cell or pancreas for the treatment of the metabolic disease diabetes mellitus. ${ }^{7,8}$

Because of the complexity and serious specificity problems associated with direct electrooxidation of glucose $e^{9,10}$ the

(1) Clark, L. C., Jr.; Lyons, C. Ann. N.Y. Acad. Sci. 1962, 102, 29-45.

(2) Grundig, B.; Krabisch, C. Anal. Chim. Acta 1989, 222, 75-81.

(3) Senda, M. Ann. N.Y. Acad. Sci. 1990, 613, 79-94.

(4) Meyerhoff, M. E. Clin. Chem. 1990, 36, 1567-1572.

(5) Arnold, M. A,; Meyerhoff, M. E. CRC Crit. Rev. Anal. Chem. 1988, 20 , 149-196.

(6) Claremont, D. J.; Pickup, J.C. In Biosensors: Fundamentals and Applications Turner, A. P. F., Karube, I., Wilson, G. S., Eds.; Oxford University Press: New York, 1987; pp 356-376.

(7) Soeldner, J. S.; Change, K. W.; Aisenberg, S.; Hiebert, J. M. In Temporal Aspects of Therapeutics; Urquhart, J., Yates, F. E., Eds.; Plenum Press: New York, 1973; pp 181-207. oxidoreductase enzyme glucose oxidase (GOx) is most often used in the development of glucose sensors. This enzyme catalyses the oxidation of glucose according to the reactions

$$
\begin{aligned}
\beta \text {-D-glucose }+ \text { GOx } / \text { FAD } & \rightarrow \\
\text { D-glucono- } \delta \text {-lactone }+\mathrm{GOx} / \mathrm{FADH}_{2} & \\
\mathrm{GOx} / \mathrm{FADH}_{2}+\mathrm{O}_{2} & \rightarrow \mathrm{GOx} / \mathrm{FAD}+\mathrm{H}_{2} \mathrm{O}_{2}
\end{aligned}
$$

where FAD is the oxidized form of the prosthetic group, flavin adenine dinucleotide.

The development over the last 30 years of enzyme-based amperometric devices for glucose determination can essentially be divided into three categories. The first involves "classical" devices which monitored either the consumption of oxygen ${ }^{11}$ or the formation of hydrogen peroxide. ${ }^{12}$ Such devices were originally affected by the ambient concentration of oxygen in the sample and required a large overpotential. In order to avoid these problems "second generation" systems were developed in which the natural dioxygen in reaction $I I$ is replaced by a mediator ${ }^{3,13,14}$ resulting in electrodes which are relatively insensitive to changes in dioxygen tension and which, depending on the choice of mediator, can be operated at lower applied potentials. The successful application of these mediated systems relies on the appropriate choice of mediator, based on good kinetic interaction with the reduced enzyme $\left(\mathrm{GOx} / \mathrm{FADH}_{2}\right)$, and the effective entrapment of the mediator at the electrode surface. The latter has conventionally been achieved by the use of precast films (e.g., dialysis membranes ${ }^{13,15,16}$ and more recently using electropolymerization techniques to entrap both the mediator and enzyme in a molecular film. ${ }^{17-19}$ However, problems associated with these devices include leeching of the mediator from the membrane

(8) Velho, G. D.; Reach, G.; Thévenot, D. R. In Biosensors: Fundamentals and Applications; Turner, A.P. F., Karube, I., Wilson, G. S., Eds.; Oxford University Press: New York, 1987; pp 390-408.

(9) Vassilyev, Yu. B.; Khazova, O. A.; Nikolaeva, N. N. J. Electroanal. Chem Interfacial Electrochem. 1985, 196, 105-125.

(10) Vassilyev, Yu. B.; Khazova, O. A.; Nikolaeva, N. N. J. Electroanal. Chem. Interfacial Electrochem. 1985, 196, 127-144.

(11) Updike, S. J.; Hicks, G. P. Nature (London) 1967, 214, 986-988.

(12) Guilbault, G. G. Analytical Uses of Immobilised Enzymes; Marcel Dekker: New York, 1984.

(13) Cass, A. E. G.; Davis, G.; Francis, G. D.; Hill, H. A. O.: Aston, W. J.; Higgins, I. J.; Plotkin, E. V.; Scott, L. D. L.; Turner, A. P. F. Anal. Chem. 1984, 56 $667-671$.

(14) Crumbliss, A. L.; Hill, H. A. O.; Page, D. J. J. Electroanal. Chem. Interfacial Electrochem. 1986, 206, 327-331.

(15) Gunasingham, H.; Tan, C. H. Electroanalysis 1989, 1, 423-429

(16) Clark, L. C., Jr.; Noyes, L. K.; Spokane, R. B.; Sudan, R.; Miller, M. L. Methods Enzymol. 1988, 137, 68-89.

(17) Foulds, N. C.: Lowe, C. R. Anal. Chem. 1988, 60, 2473-2478. 
compartment of precast films and sensitivity to dioxygen tension at physiological concentrations of glucose with electropolymerized films. ${ }^{20}$

In an attempt to eliminate mediators from the reaction scheme "third generation" electrodes made from conducting organic salts have been reported. 21,22 The most common example is the TTF+ ${ }^{+} \mathrm{TCNQ}^{-}$(tetrathiafulvalenium tetracyanoquinodimethanide) electrode where it has been suggested that reduced GOx is oxidized directly at the electrode surface. ${ }^{21}$ However, the mechanism of electron transfer is controversial ${ }^{23}$ and there are also interference ${ }^{24}$ and toxicity ${ }^{25}$ problems. Thus, notwithstanding this prolific research into mediated and nonmediated enzyme electrodes, the peroxide detecting system still remains the most common form of enzyme electrode. ${ }^{26}$

As we are interested in developing a glucose sensor for neurochemical applications in the living brain, typical problems associated with analysis of such a complex biological environment include fouling by electrode poisons (e.g., proteins) and surfactants (e.g., lipids) and direct faradaic interference by endogenous electroactive species. Two of the most common interferences are the reducing agents ascorbic acid ${ }^{27}$ (AA) and uric acid, ${ }^{28}$ both of which exist in anionic form at physiological $\mathrm{pH}, 29,30$ and whose concentrations in body fluids are continuously changing. ${ }^{27,28,31}$ Recently, $\mathrm{H}_{2} \mathrm{O}_{2}$-detecting sensors based on the electropolymerization of poly(phenylenediamine) (PPD) films on Pt electrodes in which the enzyme is incorporated in the polymer film have been reported as interference-free sensors having a high enzyme activity and a low response time, making them suitable for detecting substrates in biological fluids. ${ }^{32-34}$

We recently reported preliminary results suggesting that the $\mathrm{H}_{2} \mathrm{O}_{2}$ formed by the catalytic oxidation of glucose at these electrodes is depleted by an homogeneous redox reaction involving AA in vitro. ${ }^{35}$ Because of the important implications for the reliability of a wide variety of assays involving $\mathrm{H}_{2} \mathrm{O}_{2}$ detection, including clinical analyses where negative interfer-

(18) Kajiya, Y.; Sugai, H.; Iwakura, C.; Yoneyama, H. Anal. Chem. 1991, 63, 49-54.

(19) Hale, P. D.; Boguslavsky, L. I.; Inagaki, T.; Karan, H. I.; Sui Lee, H.; Skotheim, T. A. Okamoto, Y. Anal. Chem. 1991, 63, 677-682.

(20) Cenas, N. K.; Kulys, J. J. J. Electroanal. Chem. Interfacial Electrochem. 1981, $128,103-113$.

(21) Albery, W. J.; Bartlett, P. N.; Craston, D. H. J. Electroanal. Chem. Interfacial Electrochem. 1985, 194, 223-235.

(22) Bartlett, P. N. In Biosensors: A Practical Approach; Oxford University Press: New York, 1990; pp 47-95.

(23) Bartlett, P. N. J. Electroanal. Chem. Interfacial Electrochem. 1991, 300, 175-189.

(24) Lowry, J. P.; O'Neill, R. D. J. Electroanal. Chem. Interfacial Electrochem. 1992, 334, 183-194.

(25) Heller, A.; Degani, Y. In Redox Chemistry and Interfacial Behavior of Biological Molecules; Dryhurst, G., Niki, K., Eds.; Plenum Press: New York, 1988; pp 151-171.

(26) Methods in Enzymology; Mosbach, K., Ed.; Academic Press: New York, 1988: Vol. 137.

(27) Grunewald, R. A.; O'Neill, R. D.; Fillenz, M.; Albery, W. J. Neurochem. Int. 1983, 5, 773-778.

(28) Cespuglio, R.; Sarda, N.; Gharib, A.; Faradji, H.; Chastrette, N. Exp. Brain Res. 1986, 64, 589-595.

(29) Youngblood, M. P. J. Am. Chem. Soc. 1989, 111, 1843-1849

(30) Dryhurst, G.; Kadish, K. M.; Scheller, F.; Renneberg, R. Biological Electrochemistry; Academic Press: New York, 1982; Vol. 1, Chapter 5.

(31) O'Neill, R. D. Brain Res. 1990, 507, 267-272.

(32) Sasso, S. V.; Pierce, R. J.; Walla, R.; Yacynych, A. M. Anal. Chem. 1990, 62, 1111-1117.

(33) Malitesta, C.; Palmisano, F.; Torsi, L.; Zambonin, P. G. Anal. Chem. 1990, $62,2735-2740$.

(34) Lowry, J. P.; O'Neill, R. D. Electroanalysis, in press.

(35) Lowry, J. P.; O'Neill, R. D. Anal. Chem. 1992, 64, 453-456. ence by AA in glucose monitoring has been reported recently, ${ }^{36}$ we have investigated this phenomenon further. The results support the original hypothesis and highlight the need to test each individual assay procedure involving $\mathrm{H}_{2} \mathrm{O}_{2}$ under relevant conditions for both positive and negative interference by AA. Since we are developing enzyme-based sensors for monitoring neurochemical dynamics, we have investigated the relevance of AA interference at $\mathrm{Pt} / \mathrm{PPD} / \mathrm{GOx}$ electrodes in vivo.

\section{EXPERIMENTAL SECTION}

Chemicals and Solutions. The enzyme glucose oxidase (GOx) from Aspergillus niger (EC 1.1.3.4, type VII-S), insulin from bovine pancreas, and the lipid L- $\alpha$-phosphatidylethanolamine (type II-S) were obtained from Sigma Chemical Co. Ethylenediaminetetraacetic acid (EDTA, disodium salt) and hydrogen peroxide ( $30 \%(\mathrm{w} / \mathrm{v})$ solution) were from $\mathrm{BDH}$ Chemicals Ltd., GPR grade. The exact concentration of $\mathrm{H}_{2} \mathrm{O}_{2}$ was determined by titrating against a standardized potassium permanganate solution. The o-phenylenediamine (1,2-diaminobenzene, Merck Chemical Co., $99+\%), \alpha$-D-(+)-glucose (Sigma), L-ascorbic acid (BDH, Biochemical grade), and uric acid (Sigma, sodium salt), were used as supplied. Carbon paste was prepared ${ }^{37}$ by thoroughly mixing $2.83 \mathrm{~g}$ of carbon powder (UCP-1-M, Ultra Carbon Corp., Bay City, MI) and $1.0 \mathrm{~mL}$ of silicone oil (Aldrich, Catalog No. 17 563-3).

A stock $1 \mathrm{~mol} / \mathrm{L}$ solution of glucose was prepared, left for $24 \mathrm{~h}$ at room temperature to allow equilibration of the anomers, and then stored at $4^{\circ} \mathrm{C}$. Hydrogen peroxide solutions (100 $\mathrm{mmol} / \mathrm{L}$ ) were prepared just before use by dilution of the commercial $30 \%$ stock solution. AA solutions ( $100 \mathrm{mmol} / \mathrm{L}$ ) for experiments in vitro were also prepared just before use because of their gradual decomposition, while EDTA solutions $(100 \mathrm{mmol} / \mathrm{L})$ were used within $48 \mathrm{~h}$ of preparation. AA solutions $(0.34 \mathrm{~g} / \mathrm{mL})$ used for experiments in vivo were prepared just before use, and the $\mathrm{pH}$ was adjusted to between 6.5 and 7.0 using $\mathrm{NaOH}$. The insulin solution was prepared in PBS $(4.0 \mathrm{mg} / 25 \mathrm{~mL})$ and remained cloudy even after sonication for ca. $15 \mathrm{~min}$. Experiments in vitro were carried out in a phosphate buffer saline (PBS) solution, $\mathrm{pH}$ 7.4: $\mathrm{NaCl}$ (Merck, BP USP grade, $0.15 \mathrm{~mol} / \mathrm{L}), \mathrm{NaH}_{2} \mathrm{PO}_{4}(\mathrm{BDH}$, AnalaR grade, $0.04 \mathrm{~mol} / \mathrm{L})$, and $\mathrm{NaOH}$ (BDH, GPR grade, $0.04 \mathrm{~mol} / \mathrm{L}$ ). All solutions were prepared using distilled water and were kept refrigerated when not in use.

Atomic absorption spectroscopy of the PBS indicated that it contained ca. $1 \mu \mathrm{mol} / \mathrm{L}$ copper and $3 \mu \mathrm{mol} / \mathrm{L}$ iron impurities. The level of these metals in the distilled water and AA and glucose reagents was negligible.

Instrumentation and Software. All experiments were microcomputer controlled with data collection accomplished using either a Biodata Microlink interface or a National Instruments (NI, Austin, TX) AT-MIO-16 data acquisition board and a specially designed low-noise, low-damping potentiostat. In-house software was written in QuickBASIC (version 4.0) and NI LabWindows (version 2.1) QuickBASIC environments to perform all voltammetric experiments and to collect, plot, and analyze the data. The enzyme parameters $V_{\max }, K_{\mathrm{m}}$, and $\alpha$ (see Data Analysis below) were obtained by

(36) Strijdom, J. G.; Marais, B. J.; Koeslag, J. H. S. Afr. Med.J. 1993, 84, 64-65. (37) O'Neill, R. D.; Grunewald, R. A.; Fillenz, M.; Albery, W. J. Neuroscience 1982, 7, 1945-1954. 
using the nonlinear regression data analysis computer package Enzfitter (Elsevier-Biosoft, version 1.05).

Working Electrode Preparation. Glucose oxidase was immobilized in poly ( $o$-phenylenediamine) films by potentiometric electropolymerization of the monomer $(300 \mathrm{mmol} / \mathrm{L})$ on the bare disk end of a freshly cut Teflon-insulated Pt wire (Plastics One Inc., Virginia). The codeposition procedure was similar to that reported by Malitesta et al. ${ }^{33}$ and Almeida et al. ${ }^{38}$ Briefly, a deoxygenated solution of the monomer (300 $\mathrm{mmol} / \mathrm{L}$ ) was prepared in PBS. An aliquot of $5 \mathrm{~mL}$ of this solution was then added to a weighed quantity of GOx (5 $\mathrm{mg} / \mathrm{mL}$ ) in a $10-\mathrm{mL}$ beaker and the solution sonicated for approximately $2 \mathrm{~min}$ to ensure complete dissolution of the enzyme. The reference (SCE) and auxiliary (large Pt wire) electrodes were then immediately connected and the electropolymerization procedure was begun. The working electrode potential was maintained at $+0.65 \mathrm{~V}$ versus SCE for 15 min, although 10 min was sufficient to reach the small steadystate current indicative of this self-sealing process. ${ }^{32}$ After the electropolymerization, the Pt/PPD/GOx electrodes were rinsed by immersion in PBS for $30 \mathrm{~min}$ to remove loosely bound enzyme and unreacted monomer.

The carbon paste working electrodes (CPEs) were made from Teflon-coated silver wire ${ }^{37}$ (Clark Electromedical Instruments, Reading). The Teflon insulation was slid along the wire to create an approximately $2 \mathrm{~mm}$ deep cavity. Further slipping of the Teflon was prevented by bending the wire at the opposite end to the cavity. The cavity was packed with carbon paste using a silver wire as plunger. A small gold electrical contact was attached to the end of the wire. The carbon powder electrode (CPWEs) were prepared in the same way except that the Teflon cavity was filled with the unpasted carbon powder. Glucose oxidase adsorption onto the CPWEs was accomplished by dipping the electrode tip in the enzyme powder until the surface was completely coated and then dropping a sufficient volume of PBS $(0.1-0.2 \mu \mathrm{L})$ onto the electrode surface to apparently dissolve the enzyme. The active diameter of the disk electrodes was $250 \mu \mathrm{m}$ with a $320-\mu \mathrm{m}$ external diameter. When not in use all electrodes were stored in PBS at $4^{\circ} \mathrm{C}$.

Voltammetry in Vitro. All experiments in vitro were performed in a standard three-electrode glass electrochemical cell which was thermostated at $25.0 \pm 0.5^{\circ} \mathrm{C}$. The working electrodes used were either bare Pt disks, PPD/GOx-modified $\mathrm{Pt}$, or GOx-modified carbon powder electrodes. A saturated calomel electrode (SCE) was used as the reference electrode, and a large silver wire, isolated in a compartment containing PBS, served as the auxiliary electrode. The applied potentials for these amperometric studies were $+0.7 \mathrm{~V}$ versus SCE for the $\mathrm{Pt} / \mathrm{PPD} / \mathrm{GOx}$ electrodes, which is the value generally used for $\mathrm{H}_{2} \mathrm{O}_{2}$ detection $32,33,38$ and $+0.78 \mathrm{~V}$ versus $\mathrm{SCE}$ for the CPWEs. The current was measured when the solution was quiescent unless otherwise stated. To facilitate mixing in calibration experiments, solutions were bubbled with air using a RENA 101 air pump for ca. $10 \mathrm{~s}$ following the addition of each aliquot; the current was then measured when the solution was quiescent. In hydrodynamic experiments solutions were stirred at ca. $5 \mathrm{~Hz}$ throughout the current sampling.

(38) Almeida, N. F.; Wingard, L. B. Jr.; Malmros, M. K. Ant. N.Y. Acad. Sci. $1990,613,448-451$.
Voltammetry in Vivo. Male Sprague-Dawley rats (ca. 300 g initial weight) were stereotaxically implanted, under chloral hydrate anaesthesia $(3.5 \mathrm{~mL} / \mathrm{kg}$ i.p., $10 \%$ solution in normal saline), with working electrodes in specific brain structures as described in detail. ${ }^{37}$ The working electrode combination was either a PPD/GOx-modified Pt electrode and a CPE or bilateral CPEs placed in the right and left dorsal striatum, respectively. The coordinates used, with the skull leveled between bregma and lambda, were: AP $-0.5 \mathrm{~mm}$ (from bregma), $\mathrm{L} \pm 3.0 \mathrm{~mm}, \mathrm{DV}-4.8 \mathrm{~mm}$ (from skull). Silver wires $(250 \mu \mathrm{m})$ placed in the cortex served as reference and auxiliary electrodes. The reference potential provided by the Ag wire in brain tissue is very similar to that of the SCE. ${ }^{39}$ The animals were placed in the recording cage immediately after surgery, connected to the recording equipment, and left to recover for at least $24 \mathrm{~h}$. The light/dark cycle was the same as that of the presurgery housing room: $12 / 12 \mathrm{~h} \mathrm{light/}$ dark with lights on at 8 a.m. Food and water were available ad libitum. The protocol for these experiments was approved by the college President's committee on animal welfare.

Staircase voltammograms were recorded with CPEs at 12min intervals at a scan rate of either 10 or $50 \mathrm{mV} / \mathrm{s}$. Currentvoltage plots show a distinct peak between 0 and $300 \mathrm{mV}$. The peak, centered at about $200 \mathrm{mV}$, corresponds to the oxidation of AA present in the extracellular fluid (ECF) around the electrode tip. ${ }^{39,40}$ The height of the peak, $h$, was measured by constructing a baseline between the two minima and measuring the distance from this to the current maximum. The value of potential for the amperometric experiments with CPEs was selected from these linear sweep recordings. A potential of $+0.2 \mathrm{~V}$ was chosen as this was just above the peak potential for AA oxidation. ${ }^{40}$ Amperometry was carried out at the $\mathrm{Pt} / \mathrm{PPD} / \mathrm{GOx}$ electrode in vivo at a potential of +0.7 V.

Data Analysis. Because of the classical nonlinearity of enzyme/substrate calibrations both in solution and for immobilized enzymes, ${ }^{41}$ the apparent Michaelis-Menten constants, $V_{\max }(\mathrm{nA})$ and $K_{\mathrm{m}}(\mathrm{mmol} / \mathrm{L})$, were determined using the following Hill-type equation

$$
I=\frac{V_{\max }}{1+\left(\frac{K_{\mathrm{m}}}{\text { [gluc }]}\right)^{\alpha}}
$$

where the current $I$ is a measure of the rate of reaction and $\alpha$ is used as a measure of the deviation from ideal MichaelisMenten behavior.

All data are reported as mean \pm SEM. The significance of differences observed was estimated using Student's twotailed $t$-tests. Paired tests were used for comparing signals recorded with the same electrode (e.g., before and after drug administration); unpaired tests were used for comparing data from different electrodes.

\section{RESULTS AND DISCUSSION}

Glucose Calibrations. Figure 1 (top) illustrates the effect on the amperometric current of adding an aliquot of glucose

(39) O'Neill, R. D. Analyst 1993, 118, 433-438.

(40) Boutelle, M. G.; Svensson, L.; Fillenz, M. Neuroscience 1989, 30, 11-17.

(41) Inoue, Y.; Kato, Y.; Sato, K. J. Chem. Soc., Faraday Trans. 1992, 88, 449454. 

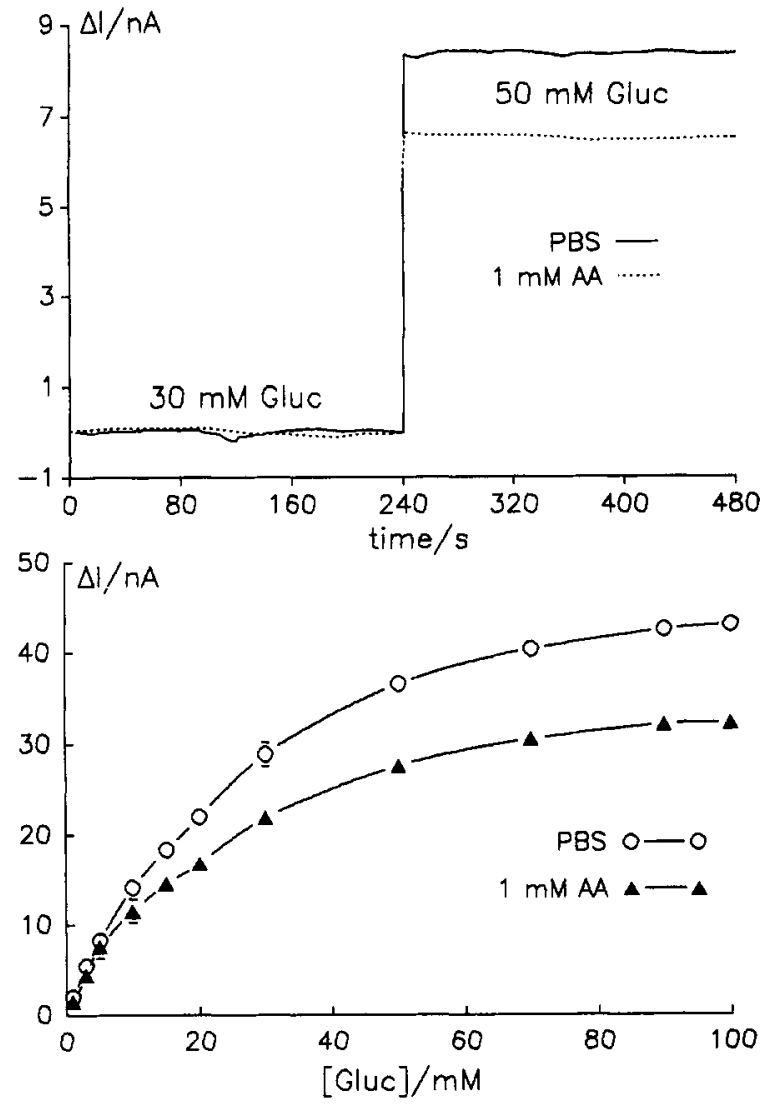

Flgure 1. (top) Examples of the amperometric current increment ( $\Delta$ I) recorded with a Pt/PPD/GOx electrode at $700 \mathrm{mV}$ versus SCE for the addition of $20 \mathrm{mmol} / \mathrm{L}$ glucose into a PBS solution containing either $30 \mathrm{mmol} / \mathrm{L}$ glucose or $30 \mathrm{mmol} / \mathrm{L}$ glucose plus $1 \mathrm{mmol} / \mathrm{L}$ ascorbate (AA). (bottom) Glucose calibrations of Pt/PPD/GOx electrodes $(n=$ 3 ) in the range $0-100 \mathrm{mmol} / \mathrm{L}$ glucose carried out elther in PBS or a solution of $1 \mathrm{mmol} / \mathrm{L}$ AA in PBS. The ordinate is $\Delta I$ since the current recorded at zero glucose concentration has been subtracted. See Glucose Calibrations.

to a quiescent solution recorded with a Pt/PPD/GOx electrode at $0.7 \mathrm{~V}$ vs SCE. The response time was satisfactory, with the $95 \%$ steady-state response being achieved in less than the mixing time (ca. $10 \mathrm{~s}$ ), as reported by Malitesta et al. ${ }^{33} \mathrm{~A}$ similar response time was observed in hydrodynamic studies. This behavior is not unexpected as there is evidence that PPD films formed under similar conditions have a thickness of the order of 5-10 nm ${ }^{33,42}$ so that GOx molecules (diameter ca. 9 $\mathrm{nm}^{43}$ ) would be located at the polymer/electrolyte interface ${ }^{32}$ (see Figure 4, later). The increase in current, however, caused by adding glucose was clearly less in the presence of $1 \mathrm{mmol} / \mathrm{L}$ AA compared with its absence. There are at least three possible mechanisms that would lead to reduced sensitivity to glucose in the presence of AA: (i) fouling of the Pt surface by AA; (ii) "clogging" of the membrane by AA; (iii) a homogeneous reaction between AA and $\mathrm{H}_{2} \mathrm{O}_{2}$ (reaction IV). This reaction has recently been observed at bare $\mathrm{Pt}$ electrodes, ${ }^{35}$ and homogeneous interference by $\mathrm{H}_{2} \mathrm{O}_{2}$ in AA detection ${ }^{44}$ and by $\mathrm{AA}$ in a spectrochemical assay for oxalate ${ }^{45}$ has also

(42) Ohnuki, Y.; Matsuda, H.; Ohsaka, T.; Oyama, N. J. Electroanal. Chem. Interfacial Electrochem. 1983, 158, 55-67.

(43) Nakamura, S.; Hayashi, S.; Koga, K. Biochim. Biophys. Acta 1976, 445, 294-308.

(44) Matuszewski, W.; Trojanowicz, M. Electroanalysis 1990, 2, 147-153.

(45) Inamdar, K. V.; Raghavan, K. G.; Pradhan, D. S. Clin. Chem. 1991, 37, 864-868. been reported. To investigate more fully the processes involved, we next quantified the glucose and AA concentration dependence of this negative interference.

$$
\mathrm{H}_{2} \mathrm{O}_{2}+\text { ascorbic acid } \stackrel{\mathrm{M}^{2+}}{\rightarrow} 2 \mathrm{H}_{2} \mathrm{O}+\text { dehydroascorbic acid }
$$

Calibration plots for 0-100 mmol/L glucose for Pt/PPD/ GOx electrodes in the presence and absence of $1 \mathrm{mmol} / \mathrm{L} \mathrm{AA}$ are shown in Figure 1 (bottom). The calibrations followed Michaelis-Menten kinetics in both cases, since $\alpha$ (see eq III) was not significantly different from unity in the absence ( 1.03 $\pm 0.02)$ or presence $(0.96 \pm 0.04, n=3, p>0.2)$ of AA. Although $K_{\mathrm{m}}$ was similar under the two conditions (AA absent, $29 \pm 3 \mathrm{mmol} / \mathrm{L}$; AA present, $29 \pm 4 \mathrm{mmol} / \mathrm{L}, n=3, p>0.9$ ), the $V_{\max }$ value calculated for PBS solutions, $44 \pm 8 \mathrm{nA}(n=$ $3)$, was reduced by $24 \pm 6 \%(p<0.05)$ by $1 \mathrm{mmol} / \mathrm{L} \mathrm{AA}$. Similar percentage decreases were observed over the range of glucose concentrations studied (Figure 1, bottom) ranging from $22 \pm 9 \%(n=3)$ at $1 \mathrm{mmol} / \mathrm{L}$ glucose to $25 \pm 5 \%(n$ $=3$ ) at $100 \mathrm{mmol} / \mathrm{L}$. This reduction was less than that reported in our recent correspondence ${ }^{35}$ because the decrease in electrode sensitivity to glucose over time was not taken into account in the earlier work. By use of stability data, ${ }^{34}$ the recalculated reduction in $V_{\max }$ for $500 \mu \mathrm{mol} / \mathrm{L}$ AA reported previously was $30 \pm 13 \%, n=3$.

The GOx activity of the PPD electrodes used in this study compares well with previous reports. ${ }^{33}$ The current density corresponding to the $V_{\max }$ value calculated from calibrations in PBS was $88 \pm 15 \mu \mathrm{A} / \mathrm{cm}^{2}(n=10)$.

Ascorbate Amperometric Titrations. To ensure saturation of the enzyme by glucose in these experiments, the maximum flux of $\mathrm{H}_{2} \mathrm{O}_{2}$ was generated ( $66 \pm 7 \mathrm{nA}, n=3$ ) using a concentration of glucose $(100 \mathrm{mmol} / \mathrm{L})$ well in excess of the $K_{\mathrm{m}}$. The amperometric glucose current at $0.7 \mathrm{~V}$ was recorded as a function of AA concentration $(0-10 \mathrm{mmol} / \mathrm{L})$ in order to determine the AA concentration dependence of the negative interference. Injection of AA aliquots into the cell containing $100 \mathrm{mmol} / \mathrm{L}$ glucose produced a rapid decrease in the current that reached a new relatively stable value (inset Figure 2); the increases associated with direct oxidation of AA were negligible due to the blocking effect of the polymer film..$^{32,33,35,42,46}$ The half-life of this response to AA was similar for each AA addition at ca. $30 \mathrm{~s}$. The low-frequency fluctuations in the glucose signal (see inset Figure 2) which were often observed in the presence of $\mathrm{AA}$ may be due to oscillation reactions between the $\mathrm{H}_{2} \mathrm{O}_{2}$ and $\mathrm{AA}$, as has been reported in other $\mathrm{H}_{2} \mathrm{O}_{2}$-containing systems. ${ }^{47,48}$ A plot of normalized steadystate currents for three electrodes versus AA concentration is shown in Figure 2. The glucose current was very sensitive to $\mathrm{AA}$ at low concentrations giving a half-maximum decrease of $22 \pm 6 \%(n=3)$ at ca. $300 \mu \mathrm{mol} / \mathrm{L}$ AA. The effective maximum decrease $(38 \pm 8 \%, n=3)$ was observed at $2 \mathrm{mmol} / \mathrm{L}$ since this was not significantly different from the value at 10 $\mathrm{mmol} / \mathrm{L}(45 \pm 7 \%, n=3)$. The fit of these data to an exponential decay curve was good (eq $\mathrm{V}, r=0.959$ ) considering

(46) Cheek, G.; Wales, C. P.; Nowak, R. J. Anal. Chem. 1983, 55, 380-381.

(47) Mori, Y.; Hanazaki, I. J. Phys. Chem. 1992, 96, 9083-9087.

(48) Koper, M. T. M.; Meulenkamp, E. A.; Vanmaekelbergh, D. J. Phys. Chem. $1993,97,7337-7341$. 


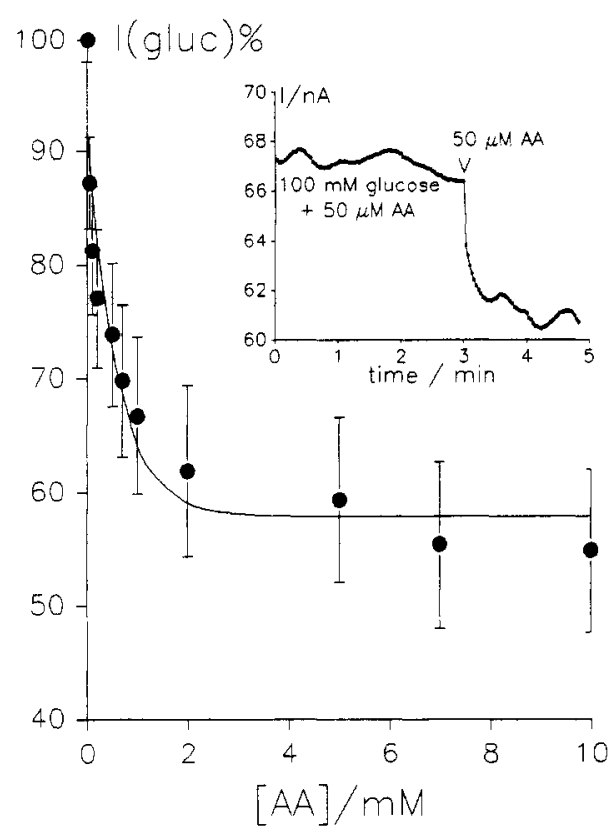

Figure 2. Normalized steady-state $100 \mathrm{mmol} / \mathrm{L}$ glucose current at Pt/PPD/GOx electrodes $(n=3)$ as a function of ascorbate (AA) concentration between 0 and $10 \mathrm{mmol} / \mathrm{L}$. The half-maximum decrease was observed at ca. $300 \mu \mathrm{mol} / L \mathrm{AA}$ and the maximum decrease was $45 \pm 7 \%$. The nonlinear regression curve is given by eq V. Inset: Example of the effect of an AA injection on the absolute amperometric current. See Ascorbate Amperometric Titrations.

the experimental error. A model for this behavior is proposed below.

$I(\%)=$

$$
(58 \pm 2 \%)+(34 \pm 4 \%) \exp \left\{\left(-1.7 \pm 0.5 \mathrm{mM}^{-1}\right)[\mathrm{AA}]\right\}(\mathrm{V})
$$

To test the possibility that $A A$ was interfering with transport through the PPD membrane, the effect of AA on the glucose response obtained at membrane-free GOx-modified CPWEs was investigated. The current density corresponding to the $100 \mathrm{mmol} / \mathrm{L}$ glucose response at these membrane-free electrodes was $215 \pm 17 \mu \mathrm{A} / \mathrm{cm}^{2}(n=3)$, indicating both good loading and activity of the adsorbed enzyme and good reproducibility of the adsorption method. When $100 \mathrm{mmol} / \mathrm{L}$ glucose was added to PBS containing $1 \mathrm{mmol} / \mathrm{L} \mathrm{AA}$, the increase in current recorded with the GOx-modified CPWEs was $37 \pm 11 \%(n=3, p<0.04)$ smaller than that obtained with the same electrodes for similar additions of glucose into PBS alone. The finding that this value was not significantly different from the decrease $(33 \pm 7 \%, n=3, p<0.03)$ observed for corresponding concentrations at Pt/PPD/GOx electrodes indicates that interference with transport through the PPD membrane is not responsible for the depression by AA of the glucose sensitivity at $\mathrm{Pt} / \mathrm{PPD} / \mathrm{GOx}$ electrodes.

Titrations of urate $(0-100 \mu \mathrm{mol} / \mathrm{L})$ had no significant effect on the glucose current recorded in experiments similar in design to those for AA. We thus conclude that urate does not interact appreciably with $\mathrm{H}_{2} \mathrm{O}_{2}$ in solution, as suggested by Tyagi and Dryhurst. ${ }^{49}$

EDTA Studies. Previous reports in the literature of the presence of a homogeneous redox reaction between AA and

(49) Tyagi, S. K.; Dryhurst, G. J. Electroanal. Chem. Interfacial Electrochem $1984,174,343-364$.
$\mathrm{H}_{2} \mathrm{O}_{2}$ (reaction IV) suggest that it only occurs in the presence of a catalyst, e.g., small amounts of heavy metal ions $\left(\mathrm{Fe}^{3+}\right.$ and $\mathrm{Cu}^{2+}, 50-52$ or peroxidase enzymes (ascorbate peroxidase ${ }^{53}$ and horseradish peroxidase ${ }^{54}$ ). Even when the reaction was observed in the absence of added catalysts, it was assumed to be promoted by impurities in the buffer..$^{50}$ To test the possibility that the homogeneous reaction(IV) was occurring at Pt/PPD/GOx electrodes, catalyzed by metal ion impurities in the PBS, we investigated the effect of the chelator EDTA, which has been used to inhibit the metal catalyzed oxidation of AA. ${ }^{55,56}$ In the absence of EDTA the $100 \mathrm{mmol} / \mathrm{L}$ glucose current was reduced by the addition of $1 \mathrm{mmol} / \mathrm{L}$ AA from $38 \pm 3 \mathrm{nA}$ to $27 \pm 3 \mathrm{nA}(n=9)$, representing an average decrease of $29 \pm 5 \%(p<0.001)$. In the presence of EDTA $(1 \mathrm{mmol} / \mathrm{L})$, however, addition of AA did not affect the glucose response: $52 \pm 7 \mathrm{nA}(n=5)$ before AA to $52 \pm 7 \mathrm{nA} 5 \mathrm{~min}$ later $(p>0.9)$. This one particular finding provides strong evidence that the reduced sensitivity of Pt/PPD/GOx electrodes to glucose in the presence of AA (Figures 1 and 2) is not due to either fouling of the Pt surface by AA as suggested recently ${ }^{57}$ or "clogging" of the membrane by $\mathrm{AA}$, but to an homogeneous reaction between $\mathrm{AA}$ and $\mathrm{H}_{2} \mathrm{O}_{2}$ (reaction IV).

It was noted that addition of $1 \mathrm{mmol} / \mathrm{L}$ EDTA caused a small, marginally significant, increase in the $100 \mathrm{mmol} / \mathrm{L}$ glucose current of $2.2 \pm 0.8 \%, n=5, p<0.07$, but no increase when glucose was absent from the solution. This may be due to a blocking by EDTA of either heavy metal catalyzed degradation of $\mathrm{H}_{2} \mathrm{O}_{2}{ }^{58,59}$ or heavy metal inhibition of GOx. ${ }^{60}$

Since the proposed homogeneous redox reaction would take place near the Pt/PPD/GOx surface, and might be affected by it, we examined the extent of this negative interference reaction in the bulk solution to determine whether the problem might have a more general significance. Amperometric peroxide calibrations ( $0-1 \mathrm{mmol} / \mathrm{L}$ ) for unmodified bare $\mathrm{Pt}$ disk electrodes at $+0.7 \mathrm{~V}$ vs SCE were performed in PBS (containing low micromolar background levels of heavy metal ions, see Chemicals and Solutions) in the presence of either $\mathrm{AA}(1 \mathrm{mmol} / \mathrm{L})$ or AA $(1 \mathrm{mmol} / \mathrm{L})$ and EDTA $(1 \mathrm{mmol} / \mathrm{L})$. When EDTA and AA were both present, the concentration steps were well-defined for each addition of $\mathrm{H}_{2} \mathrm{O}_{2}$ (Figure 3, top). The calibration slope was $40 \pm 13 \mathrm{nA} / \mathrm{mM},(n=4)$, which is in the range expected-between fresh Pt disks (112 $\pm 8 \mathrm{nA} / \mathrm{mM}, n=11$ ) and surfaces several weeks old (28 \pm $3 \mathrm{nA} / \mathrm{mM}, n=5$ ). When EDTA was absent from the AA solution, the injection of $\mathrm{H}_{2} \mathrm{O}_{2}$ resulted in an initial increase in current which decayed with an average half-life of $33 \pm 10$ $\mathrm{s}(n=8)$ and a pseudo-first-order rate constant of $(3.2 \pm 0.6)$ $\times 10^{-2} \mathrm{~s}^{-1}(n=8)$, for the metal ion catalyzed homogeneous reaction (Figure 3, bottom). The $\mathrm{H}_{2} \mathrm{O}_{2}$ calibration slope in the absence of EDTA was significantly reduced to $7 \pm 3 \mathrm{nA} /$ $\mathrm{mM}(n=4), p<0.001$ compared with EDTA present. Thus,

(50) Hand, D. B.; Greisen, E. C. J. Am. Chem. Soc. 1942, 64, 358-361.

(51) DeChatelet, L. R.; Cooper, M. R.; McCall, C. E. Antimicrob. Agents Chemother. 1972, l, 12-16.

(52) Timberlake, C. F. J. Sci. Food Agric. 1960, 11, 268-273.

(53) Kelly, G. J.; Latzko, E. J. Agric. Food Chem. 1980, 28, 1320-1321.

(54) Maidan, R.; Heller, A. Anal. Chem. 1992, 64, 2889-2896.

(55) Butt, V. S.; Hallaway, M. Arch. Biochem. Biophys. 1961, 92, 24-32.

(56) Deutsch, J. C.; Kolhouse, J. F. Anal. Chem. 1993, 65, 321-326.

(57) Palmisano, F.; Zambonin, P. G. Anal. Chem. 1993, 65, 2690-2692

(58) Aruoma, O. I. Chem. Br. 1993, 29, 210-214.

(59) Dekker, A. O.; Dickinson, R. G. J. Am. Chem. Soc. 1940, 62, 2165-2171.

(60) Nakamura, S.; Ogura, Y. J. Biochem. (Tokyo) 1968, 64, 439-447. 

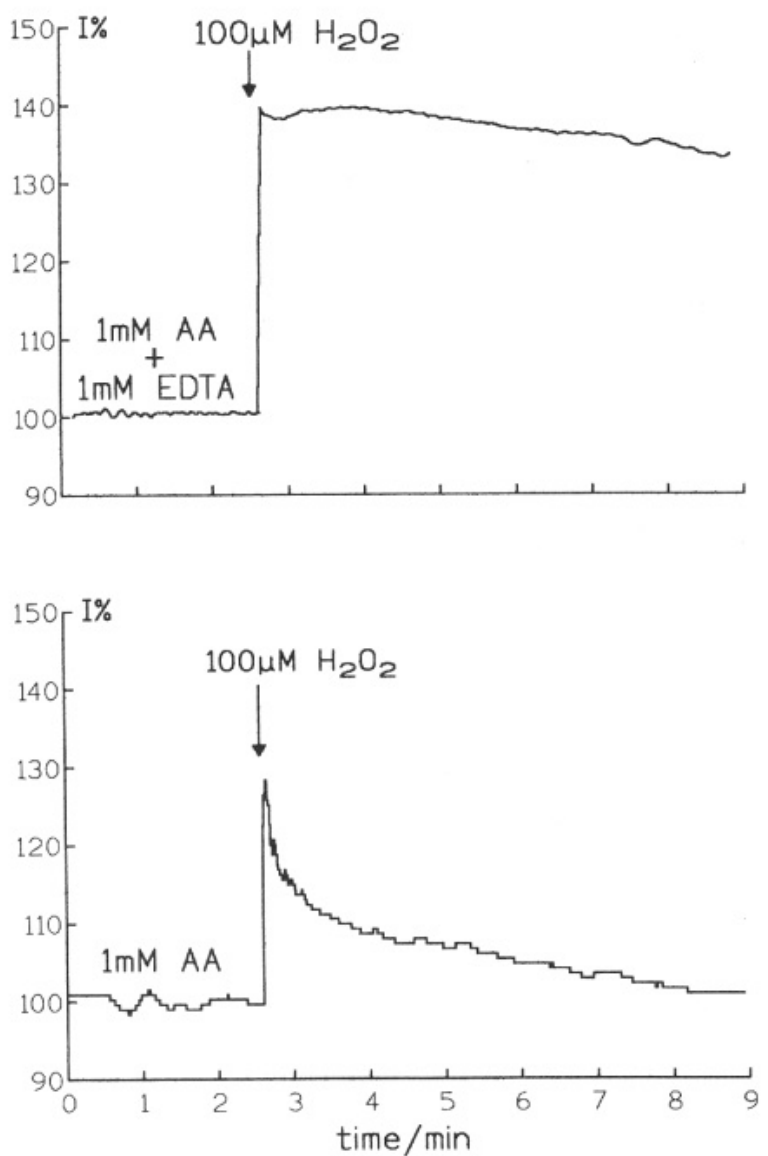

Figure 3. Normalized amperometric response recorded with a bare $125-\mu \mathrm{m}$-radius Pt-disk electrode at $700 \mathrm{mV}$ versus SCE for the addition of $100 \mu \mathrm{M} \mathrm{H}_{2} \mathrm{O}_{2}$ into a PBS solution containing $1 \mathrm{mM}$ ascorbate (AA) +1 mM EDTA (top) or 1 mM AA (bottom). See EDTA Studies.

these results clearly indicate that $\mathrm{H}_{2} \mathrm{O}_{2}$ detection in the presence of AA in buffers containing metal ion impurities is unreliable without protection by EDTA.

It has been reported that the amount of heavy metals such as $\mathrm{Cu}^{2+}$ in potential systems for assay such as fruit juice is sufficient to catalyze AA oxidation, and possibly also homogeneous reaction IV. ${ }^{52}$ Since these metal ion catalysts may also be present in reagents and be inherent to most systems, it is important to test for the presence of the homogeneous reaction in the development of any assay involving peroxide detection in the presence of AA. The importance of this is highlighted by comparing two commercially available peroxide detecting glucose systems. Recently, for example, the use of Dextrostix in the analysis of blood glucose levels has been seriously questioned because of the appearance of a homogeneous reaction. ${ }^{36}$ It was reported that AA competes with the dye in dextrostix for the GOx-generated $\mathrm{H}_{2} \mathrm{O}_{2}$ causing spuriously low blood glucose measurements. In contrast, the YSI Model 23 AM glucose analyzer when screened with 250 substances at their highest naturally occurring plasma level, including AA at a concentration of $11 \mathrm{mmol} / \mathrm{L}$, showed no evidence of interference. ${ }^{61}$ This may be explained by comparing the design of both systems and the different circumstances under which the two systems are used. Dextrostix has no protective membranes and is usually used by

(61) Model 23AM Glucose Analyser Instruction Manual; Yellow Springs Instruments (YSI): Yellow Springs, OH; pp 3-53.



Figure 4. Model for the metal ion $\left(\mathrm{M}^{2+}\right)$ catalyzed homogeneous interaction between solution ascorbate (AA) and the surface generated $\mathrm{H}_{2} \mathrm{O}_{2}$ from the enzymatic oxidation of glucose by glucose oxidase (GOX) at Pt/PPD/GOx electrodes. F represents different components of the $\mathrm{H}_{2} \mathrm{O}_{2}$ flux density. See Model for the Homogeneous Reaction.

diabetic patients as a fast method of determining glucose levels in untreated samples. The YSI analyzer in contrast is used in clinical laboratories and the samples are treated with preservatives and EDTA as an anticoagulant. ${ }^{61}$ The presence of EDTA, and the fact that the $\mathrm{H}_{2} \mathrm{O}_{2}$ is formed behind a protective outer polycarbonate membrane in the YSI analyzer, ${ }^{61}$ may explain the absence of negative interference from AA in this system.

Model for the Homogeneous Reaction. The model, represented in Figure 4, can be described as follows. There is evidence that PPD films formed under similar conditions have a thickness of the order of $5-10 \mathrm{~nm}^{33,42}$ so that GOx molecules (diameter ca. $9 \mathrm{~nm}^{43}$ ) would be located at the polymer/ electrolyte interface. ${ }^{32}$ In the presence of constant glucose and dioxygen concentrations, a steady-state flux of $\mathrm{H}_{2} \mathrm{O}_{2}$ per unit area, $F_{1}$, is produced as a result of the biocatalytic oxidation of glucose by GOx (reactions I and II). The $\mathrm{H}_{2} \mathrm{O}_{2}$ thus formed in either oxidized on the Pt surface, corresponding to a flux, $\mathrm{F}_{2}$, or diffuses away from the surface. $\mathrm{H}_{2} \mathrm{O}_{2}$ molecules that initially diffuse away may return to be oxidized at the surface, $F_{3}$, or be lost to the bulk solution, $F_{4}$. Thus although $F_{1}=F_{2}+F_{3}+F_{4}$, the biocatalytic glucose current, $I$, has only two components (eq 1), where $A$ is the effective electrode area and $F$ the Faraday constant.

$$
I=2 A F\left(\mathrm{~F}_{2}+\mathrm{F}_{3}\right)
$$

If AA is present in solution, its concentration at the outer polymer surface is close to the bulk value, $[\mathrm{AA}]$, because of the low permeability of the PPD film to AA..$^{32,33,35}$ The flux, $F_{2}$, would only be marginally affected by small levels of AA in the film because the membrane is also poorly permeable to the heavy metal ions needed to catalyze reaction IV. ${ }^{42} \mathrm{~F}_{3}$, however, is reduced due to the homogeneous redox process. The value of $\mathrm{F}_{4}$ is also affected by [AA] but, since this does not influence $I$, it will not be considered further.

The depletion in $\mathrm{F}_{3}$, catalyzed by $\mathrm{M}^{2+}$, can be represented by a new flux lost to the electrode, $\mathrm{F}_{5}$ (eq 2), where $k$ is a homogeneous rate constant, the magnitude of which depending 
on the concentration of $\mathrm{M}^{z+}$ among other factors.

$$
\mathrm{F}_{5}=k \mathrm{~F}_{3}[\mathrm{AA}]
$$

Thus the small decrease in the steady-state value of $F_{3},-d F_{3}$, associated with a small increase in the AA concentration, $\mathrm{d}[\mathrm{AA}]$, is given by eq 3 .

$$
-\mathrm{dF}_{3}=\mathrm{dF}_{5}=k \mathrm{~F}_{3} \mathrm{~d}[\mathrm{AA}]
$$

Therefore

$$
\frac{\mathrm{dF}_{3}}{\mathrm{~F}_{3}}=-k \mathrm{~d}[\mathrm{AA}]
$$

so that

$$
\mathrm{F}_{3}=\mathrm{F}_{3}{ }^{\circ} \exp (-k[\mathrm{AA}])
$$

where $F_{3}{ }^{\circ}$ is the value of $F_{3}$ when [AA] $=0$.

Combining eqs 1 and 5 provides an expression (eq 6) for the net glucose current in terms of [AA].

$$
I=2 A F \mathrm{~F}_{2}+2 A F \mathrm{~F}_{3}^{\circ} \exp (-k[\mathrm{AA}])
$$

The form of the plot of $I$ vs [AA] shown in Figure 2 (see eq V) agrees well with that predicted by the model with $r^{2}=$ 0.92. The term in $\mathrm{F}_{2}$ accounts for $58 \pm 2 \%$ of $I$ and $\mathrm{F}_{3}{ }^{\circ}$ for $34 \pm 4 \%$, with $k=1.7 \pm 0.5 \mathrm{mM}^{-1}, n=3$. The finding that the depression of the glucose current leveled off at high values of [AA] (Figure 2) supports the assumption that the concentration of either AA or $\mathrm{M}^{z+}$ or both is very low in the PPD film.

The validity of the model has also been tested by investigating the effect of stirring the solution on the glucose response and on the homogeneous interference by AA. The relative motion of the solution with respect to the electrode is an important parameter since the ratio $\mathrm{F}_{2} / \mathrm{F}_{3}$ should increase (i.e., $\mathrm{F}_{3}$ decrease) due to the loss of surface-generated $\mathrm{H}_{2} \mathrm{O}_{2}$ by convection for rotating electrodes, or stirred or flowing solutions, reducing the extent of homogeneous interference compared with quiescent solutions. On stirring at ca. $5 \mathrm{~Hz}$, the $100 \mathrm{mmol} / \mathrm{L}$ glucose response decreased by $18 \pm 2 \%$ ( $n$ $=8, p<0.001)$. A similar effect has also been observed at $\mathrm{Pt} / \mathrm{GOx} /$ poly $(N$-methylpyrrole) rotating disk electrodes where it was reported that as the rotation speed increased, the response decreased due to the removal of $\mathrm{H}_{2} \mathrm{O}_{2}$ from the electrode surface. ${ }^{62}$ As the enzyme is saturated at $100 \mathrm{mmol} / \mathrm{L}$ glucose in quiescent solution (see Figure 1), the hydrodynamic transport of glucose molecules to the surface associated with stirring should not in itself affect the current. In stirred solutions the decrease in the $100 \mathrm{mmol} / \mathrm{L}$ glucose current assocaited with the homogeneous reaction produced by 1 mmol/L AA was significantly smaller compared with quiescent solutions: $10 \pm 5 \%$ (stirred, $n=8$ ) and $29 \pm 6 \%$ (quiescent, $n=8$ ), with $p<0.03$. The effects on the 100 $\mathrm{mmol} / \mathrm{L}$ glucose current of stirring alone (18\% decrease), and the addition of $1 \mathrm{mmol} / \mathrm{L}$ AA to stirred solutions (further $10 \%$ decrease) were additive since a $29 \%$ decrease was observed in quiescent solutions following $1 \mathrm{mmol} / \mathrm{L} \mathrm{AA}$ addition. This indicates that the same population of $\mathrm{H}_{2} \mathrm{O}_{2}$ molecules are affected by the two processes. These results show that negative interference by AA should be much less severe in studies where

(62) Bartlett, P.N.; Whitaker, R.G.J. Electroanal. Chem. Interfacial Electrochem 1987, 224, 37-48. there is relative motion of the electrode and solution, such as in flow injection analysis, stirred solutions, and rotating disk electrode systems.

Lipid Studies. Since our main interest is the use of $\mathrm{Pt} /$ PPD/GOx electrodes for neurochemical applications in vivo, it remained to be seen whether the catalyzed homogeneous reaction effects the electrode response in vivo. Previous studies at this type of electrode have revealed minimal heterogeneous interference by reducing agents ${ }^{32,33,35,42,46}$ and virtually complete elimination of electrode fouling by proteins. ${ }^{32}$ However, before carrying out experiments in vivo it was necessary to examine the effect on the electrode response of lipids, which constitute $35 \%$ dry weight of brain tissue and have previously been reported to block the response of bare electrodes due to adsorption onto the surfaces. ${ }^{63,64}$ Furthermore, surfactants have recently been implicated in the deactivation of $\mathrm{GOx},{ }^{65}$ although older data dispute this finding. ${ }^{43}$ As recent evidence suggests that the concentration of brain extracellular glucose is ca. $1 \mathrm{mmol} / \mathrm{L}^{66,67}$ (compared with ca. $5 \mathrm{mmol} / \mathrm{L}$ assumed in previous studies $\left.{ }^{68,69}\right)$ all lipid experiments were carried out in this concentration.

There was no significant difference ( $p>0.95, n=3$ ) observed in the $1 \mathrm{mmol} / \mathrm{L}$ glucose response before $(2.1 \pm 1.0$, $n=3)$ and after $(2.2 \pm 0.9, n=3) 16 \mathrm{~h}$ continuous recording in a $10 \%$ suspension of the lipid $\mathrm{L}-\alpha$-phosphatidylethanolamine, indicating the suitability of these electrodes for applications in lipid-containing environments such as brain tissue.

Experiments in Vivo. The main aim of these experiments was to determine whether AA in brain extracellular fluid (ECF) would interfere with glucose detection using Pt/PPD/ GOx electrodes. This was achieved by monitoring simultaneously AA concentration in the left striatum with a CPE and the $\mathrm{Pt} / \mathrm{PPD} / \mathrm{GOx}$ current in the right striatum following systemic AA injections. There is evidence, however, of asymmetries between the two sides of rat brain, ${ }^{70,71}$ and so the effect of systemic AA injections on AA recorded with CPEs implanted bilaterally in the two striata was examined first. AA in rat striatum, with a baseline concentration of the order of $200-500 \mu \mathrm{mol} / \mathrm{L},{ }^{72-74}$ can be detected using CPEs and staircase voltammetry ${ }^{39}$ as a peak at ca. $200 \mathrm{mV}$. Following AA injections $(2 \mathrm{~g} / \mathrm{kg}$, i.p.), the AA peak showed a similar percentage increase on the two sides of the brain $(91 \pm 18 \%$, $n=5, p>0.70$ ) indicating that the striata are equally receptive to AA administered systemically.

(63) Ormonde, D. E.; O'Neill, R. D. J. Electroanal. Chem. Interfacial Electrochem. 1990, 279, 109-121.

(64) Nelson, A.; Auffret, N. J. Electroanal. Chem. Interfacial Electrochem. 1988, $248,167-180$

(65) Moosavimovahedi, A. A.; Housaindokht, M. R.; Moghaddasi, J. Thermochim. Acta, 1993, 219, 143-150.

(66) Harada, M.; Okuda, C.; Sawa, T.; Murakami, T. Anesthesiology 1992, 77, 728-734.

(67) Boutelle, M. G.; Fellows, L. K.; Cook, C. Anal. Chem. 1992, 64, 1790-1794.

(68) Steffens, A. B.; Scheurink, A. J. W.; Porte, D., Jr.; Woods, S. C. Am. J. Physiol. 1988, 255, R200-R204.

(69) Schalkhammer, T.; Mann-Buxbaum, E.; Urban, G.; Pittner, F. J. Chromatogr. $1990,510,355-366$.

(70) Carison, J. N.; Fitzgerald, L. W.; Keller, R. W., Jr.; Glick, S. D. Brain Res. $1991,550,313-318$.

(71) Afonso, D.; Santana, C.; Rodriguez, M. Brain Res. Bull. 1993, 32, 11-16.

(72) Amatore, C.; Kelly, R. S.; Kristensen, E. W.; Kuhr, W. G.; Wightman, R. M. J. Electroanal. Chem. Interfacial Electrochem. 1986, 213, 31-42.

(73) Gonon, F.; Buda, M.; Cespuglio, R.; Jouvet, M.; Pujol, J. F. Brain Res. 1981, $223,69-80$.

(74) Yount, S. E.; Kraft, M. E.; Pierce, R. C.; Langley, P. E.; Rebec, G. V. Life Sci. 1991, 49, 1237-1 244. 


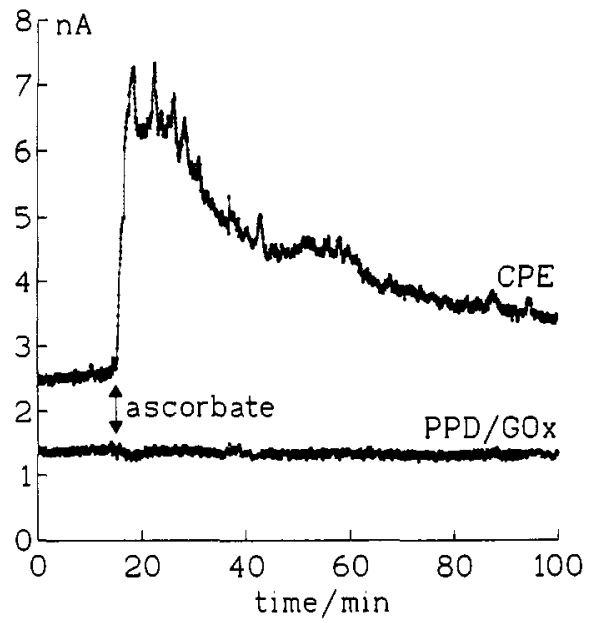

Figure 5. An example of the effect of a 2-mL intraperitoneal injection of ascorbate $(2 \mathrm{~g} / \mathrm{kg})$ on the amperometric response of a carbon paste electrode (CPE) at $200 \mathrm{mV}$ and a Pt/PPD/GOx electrode at $700 \mathrm{mV}$, implanted bilaterally in the striatum of a freely-moving rat 8 days after implantation. See Experiments in vivo.

An example of the effect of AA $(2 \mathrm{~g} / \mathrm{kg}$, i.p.) on the amperometric response of a CPE at $200 \mathrm{mV}$ and a Pt/PPD/ GOx electrode at $700 \mathrm{mV}$, recorded bilaterally in the striatum of a freely-moving rat 8 days after implantation is shown in Figure 5. In three experiments, the average AA current at the CPE increased from a basal value of $3.2 \pm 0.5 \mathrm{nA}$ to 6.2 $\pm 0.3 \mathrm{nA}(n=3, p<0.01)$ representing an average increase in response of $94 \% 15 \mathrm{~min}$ after injection. There was, however, no overall change in the response at the Pt/PPD/GOx electrode during this period: $1.6 \pm 0.3$ to $1.6 \pm 0.4 \mathrm{nA}(n=3, p>0.5$, paired test).

It is possible that the lack of response of the $\mathrm{Pt} / \mathrm{PPD} / \mathrm{GOx}$ electrode to AA was due to fouling of the electrode surface in vivo. To test this possibility, the effect of insulin (an agent known to decrease glucose levels in body fluids ${ }^{75}$ ) on the $\mathrm{Pt} /$ PPD/GOx current was examined. The injection of insulin (15 U/kg, i.p.) 12 days following sensor implantation caused a decrease in the current that was reversed by the ingestion of food (Figure 6). This suggests that Pt/PPD/GOx electrodes repond to changing glucose concentrations even after long periods in brain tissue and indicates that the lack of $\mathrm{Pt} / \mathrm{PPD} /$ GOx response to AA was due to an absence of both direct and homogeneous interference, rather than electrode fouling.

Since doubling the concentration of AA in the ECF had no effect on the Pt/PPD/GOx response, it is reasonable to conclude that the contribution from AA to the baseline current is minimal (Figure 5). A comparison with glucose calibration suggests that this current corresponds to a basal glucose level of $0.6 \pm 0.1 \mathrm{mmol} / \mathrm{L}(n=3)$, which agrees well with recent estimations. ${ }^{66,67}$

\section{CONCLUSIONS}

Detailed studies described here indicate that the previously reported homogeneous interference (reaction IV) at Pt/PPD/

(75) Chen, Z.; Steger, R. W. J. Pharmacol. Toxicol. Methods 1993, 29, 111-118.

(76) Sohn, T. W.; Stoecker, P. W.; Carp, W.; Yacynych, A. M. Electroanalysis $1991,3,763-766$.

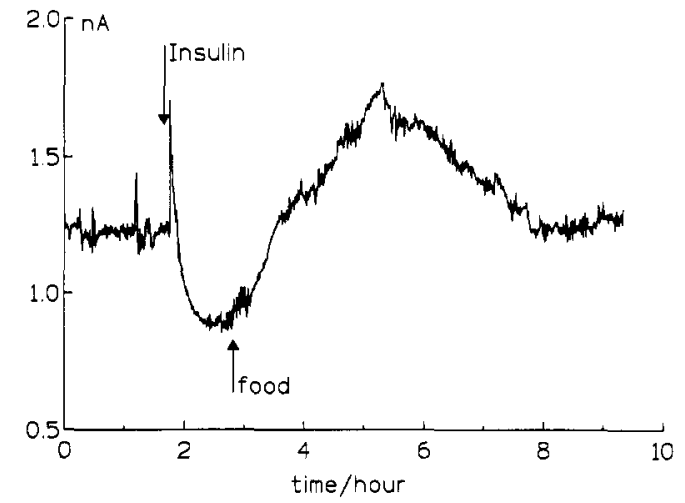

Flgure 6. Response of a Pt/PPD/GOx electrode implanted in the strlatum of a freely moving fasting rat over a $10-h$ period 12 days after sensor implantation. Injection of insulin $(15 \mathrm{U} / \mathrm{kg})$ intraperitoneally caused a decrease in the level of the signal that was reversed by the ingestion of food. See Experiments in vivo.

GOx electrodes in vitro between $\mathrm{H}_{2} \mathrm{O}_{2}$ and $\mathrm{AA}$ is catalyzed by trace metal impurities in the buffer. The presence of the metal chelator EDTA in solution eliminates this "negative" interference. Predictions of a simple model of the process, that the significance of the homogeneous reaction should be less under hydrodynamic conditions, were supported experimentally. It is clearly important, therefore, to test for the presence of the homogeneous reaction in the development of any assay system involving peroxide detection in the presence of AA. Experiments in vivo in the mammalian brain indicate the absence of the homogeneous redox reaction in this environment, presumably due to a deficiency of suitable catalysts. Previous studies $32-34,42,76$ of $\mathrm{Pt} / \mathrm{PPD} / \mathrm{GOx}$ electrodes have shown them to have a variety of characteristics including good sensitivity, rapid response time, significantly reduced interference, and freedom from protein fouling that make them suitable for glucose analysis in biological systems. We have now also shown that the properties of these electrodes are not compromized by lipids in vitro and that they remain sensitive to glucose for several days following implantation in brain tissue. Before these electrodes can be used reliably to monitor glucose dynamics in the ECF, however, further characterization is necessary, such as interference by $\mathrm{O}_{2}$.

\section{ACKNOWLEDGMENT}

We thank the Irish Science and Technology Agency (EOLAS) for a grant to A.D. under the Basic Research Awards Scheme and to J.P.L. under the Scientific Research Programme (Grant No. SC/92/304). We are also grateful to Martyn G. Boutelle, Malcolm E. McIntyre (University Laboratory of Physiology, Oxford), and Dermot Keenan for design, construction, and maintenance of the low noise potentiostat and to Mr. Liam Blake for information concerning commercial glucose analyzers.

Received for review September 14, 1993. Accepted February 23, 1994.

\footnotetext{
- Abstract published in Advance ACS Abstracts, April 1, 1994.
} 